\title{
Surgical Treatment for Ellis Type 3 Coronary Perforation During Percutaneous Catheter Intervention
}

\author{
Toshinori Totsugawa, MD; Masahiko Kuinose, MD; Hidenori Yoshitaka, MD; Keijiro Katayama, MD; \\ Yoshimasa Tsushima, MD; Atsuhisa Ishida, MD; Genta Chikazawa, MD; Arudo Hiraoka, MD
}

\begin{abstract}
Background: Coronary perforation (CP) is a rare, but sometimes lethal, complication of percutaneous catheter intervention $(\mathrm{PCl})$. We reviewed surgically-treated cases of type $3 \mathrm{CP}$ during $\mathrm{PCl}$.

Methods and Results: From 2007 to 2010, 5 patients underwent surgical repair for type 3 CP (3 men, 2 women; mean age, 74 years). The mean number of diseased coronary branches was 2.6 and the mean SYNTAX score was 45. The target lesions were the left anterior descending artery in 4 cases and the right coronary artery in 1 case. Types of American Heart Association/American College of Cardiology classification were type B2 in only one case and type $C$ in 4 cases. The causes of perforation were balloon inflation in 4 patients and rotational atherectomy in 1 patient. The in-hospital mortality rate was $20 \%$. In the cases of CP associated with balloon inflation, coronary lacerations were so severe that re-bleeding occurred even if the covered stent could temporarily achieve hemostasis, and percutaneous cardiopulmonary support and emergency surgery were required.
\end{abstract}

Conclusions: CP induced by balloon inflation tends to result in a serious condition compared with rotablatorinduced CP. Surgery should be immediately performed even after covered stent implantation if there is any possibility of re-bleeding in the case of balloon-induced type 3 CP. (Circ J 2012; 76: 377-381)

Key Words: Coronary perforation; Ellis classification; Percutaneous catheter intervention; Surgical treatment

$\mathbf{P}$ ercutaneous catheter intervention (PCI) is now undoubtedly an indispensable option for the treatment of ischemic heart disease. Although the optimal strategy of revascularization for multivessel coronary artery disease has been controversial for a long time, ${ }^{1,2}$ many interventional cardiologists today use drug-eluting stents to treat complicated coronary lesions because of the low re-stenosis rate. Current advances in stenting technique have allowed interventional cardiologists to bail out most complications; however, coronary perforation $(\mathrm{CP})$ is still a lethal complication of PCI. Ellis type 3 rupture $^{3}$ is especially associated with high morbidity and mortality; ${ }^{4}$ adequate treatment is essential to rescue such severe cases. We found several studies of CP from the viewpoint of interventional cardiologists, ${ }^{5-9}$ but there were few regarding severe $\mathrm{CP}$ requiring surgical repair, with the exception of some technical reports. ${ }^{10-12}$ We review 5 cases of surgically-treated type $3 \mathrm{CP}$ and present some lessons learned from our experience.

\section{Methods}

Between January 2007 and December 2010, 5 patients under- went surgical intervention for PCI-induced Ellis type $3 \mathrm{CP}$. Ellis classification is as follows: type $1 \mathrm{CP}$ is defined by the development of an extraluminal crater without extravasation, type $2 \mathrm{CP}$ by a pericardial or myocardial blush without contrast jet extravasation, and type $3 \mathrm{CP}$ by extravasation through a frank ( $\geq 1 \mathrm{~mm}$ ) perforation or cavity spilling into an anatomic cavity (right ventricle, coronary sinus, etc). ${ }^{3}$ Only one patient was referred to us after intensive care in another hospital; 4 cases of CP occurred in The Sakakibara Heart Institute of Okayama. Patients' demographic characteristics are summarized in Table 1 . There were 3 men and 2 women, with a mean age of 74 years (range, 55-82 years). The mean ejection fraction of the left ventricle was $62 \%$ (range, $45-71 \%$ ); the mean number of diseased coronary branches was 2.6 vessels, and the mean SYNTAX score ${ }^{13}$ was 45 (range, 27-55). All patients had undergone elective PCI for ischemic heart disease; there was no case of acute coronary syndrome (ACS). Only one patient was on dialysis and other co-morbidities were atherosclerosis obliterans in 3 patients and moderate aortic stenosis in 1 patient.

Received July 20, 2011; accepted October 20, 2011; released online December 1, 2011 Time for primary review: 49 days

Department of Cardiovascular Surgery, The Sakakibara Heart Institute of Okayama, Okayama, Japan

Present address: Department of Surgery, Division of Clinical Medical Science, Graduate School of Biomedical Sciences, Hiroshima University, Hiroshima (K.K.), Japan

Mailing address: Toshinori Totsugawa, MD, Department of Cardiovascular Surgery, The Sakakibara Heart Institute of Okayama, 2-1-10

Marunouchi, Kita-ku, Okayama 700-0823, Japan. E-mail: toshinoritotsugawa@gmail.com

ISSN-1346-9843 doi:10.1253/circj.CJ-11-0773

All rights are reserved to the Japanese Circulation Society. For permissions, please e-mail: cj@j-circ.or.jp 


\begin{tabular}{|lcr|}
\hline \multicolumn{2}{|c|}{ Table 1. Patients' Demographic Characteristics } \\
Age, years (range) & $\mathbf{n}$ & $\%$ \\
Male/female & $74 \pm 11(55-82)$ & \\
Coronary risk factor & $3 / 2$ & \\
$\quad$ Diabetes mellitus & & \\
Hypertension & 3 & 60 \\
Dyslipidemia & 5 & 100 \\
Smoking history & 4 & 80 \\
Hemodialysis & 3 & 60 \\
Acute coronary syndrome & 1 & 20 \\
SYNTAX score* & 0 & 0 \\
Intermediate SYNTAX score (23-32) & $45 \pm 12(27-55)$ & \\
$\quad$ High SYNTAX score (>33) & 1 & 20 \\
Ejection fraction (\%) & 4 & 80 \\
Diseased coronary arteries & $62 \pm 10(45-70)$ & \\
2-vessel disease & & \\
3-vessel disease & 2 & 40 \\
Comorbidity & 3 & 60 \\
$\quad$ Atherosclerosis obliterans & & \\
Aortic stenosis (moderate) & 3 & 60 \\
\hline
\end{tabular}

\begin{tabular}{|lcc|}
\hline Table 2. Lesion Morphology & $\mathbf{n}$ & $\%$ \\
Target lesion & & \\
$\quad$ Left anterior descending artery & 4 & 80 \\
$\quad$ Right coronary artery & 1 & 20 \\
Total occlusion & 0 & 0 \\
Small vessel $(<2.5 \mathrm{~mm})$ & 0 & 0 \\
Ostial lesion & 0 & 0 \\
Angulation & & \\
$\quad$ Moderate $\left(45-90^{\circ}\right)$ & 1 & 20 \\
$\quad$ Severe $\left(>90^{\circ}\right)$ & 1 & 20 \\
Bifurcation & 3 & 60 \\
Calcification & & \\
$\quad$ Moderate & 1 & 20 \\
Severe & 2 & 40 \\
Diffuse lesion $(>20 \mathrm{~mm})$ & 4 & 80 \\
AHA/ACC classification & & \\
$\quad$ Type B2 & 1 & 20 \\
Type C & 4 & 80 \\
\hline
\end{tabular}

AHA/ACC, American Heart Association/American College of Cardiology.

${ }^{*}$ Mean \pm standard deviation (range).
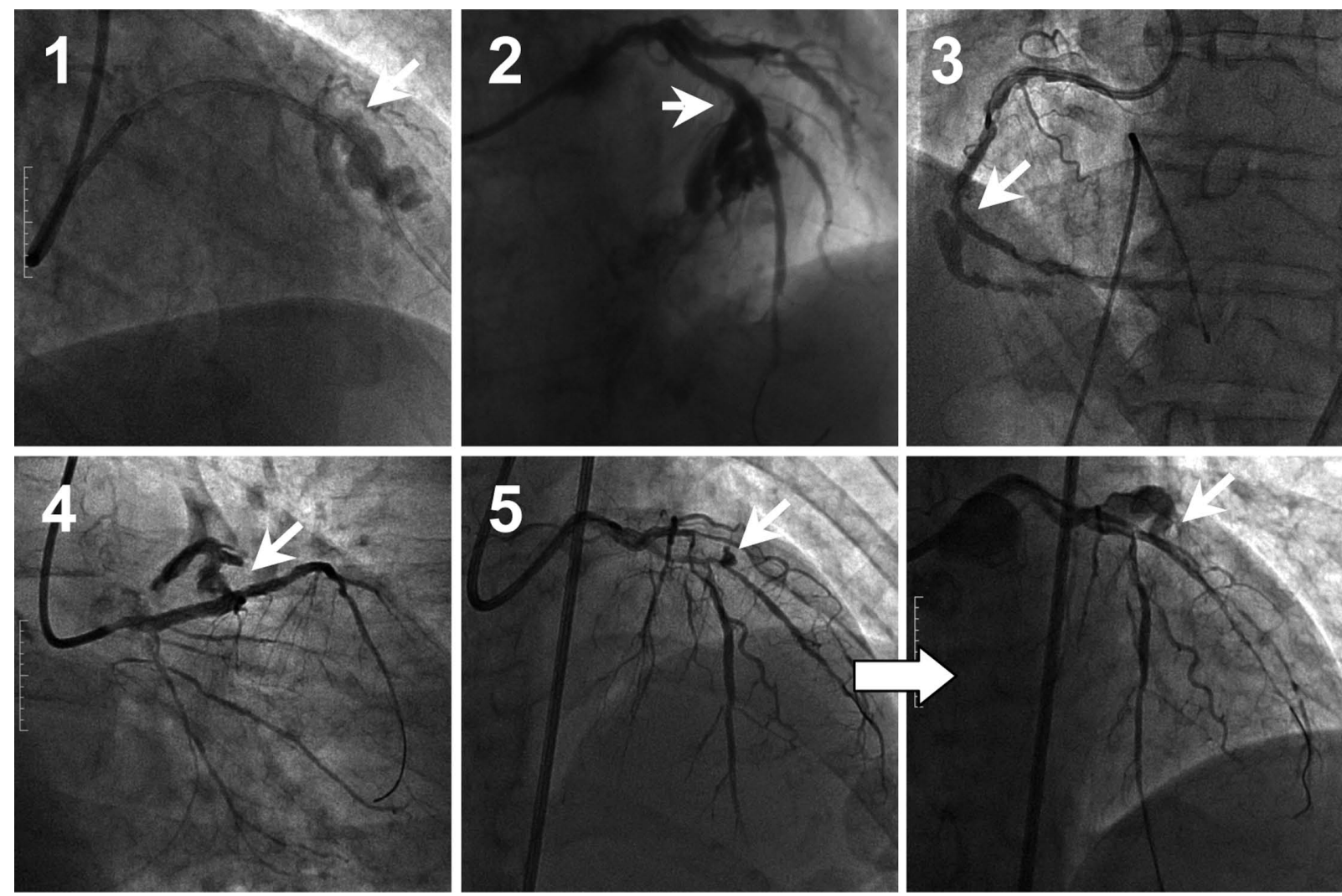

Figure 1. Coronary angiography of each case of type 3 coronary perforation (arrows). Case 1 was induced by postdilatation ballooning for segment 7. Case 2 was caused by balloon inflation for stenting at segment 7. Case 3 was the only case of rotablator-induced type 3 rupture. Case 4 was caused by balloon inflation for stenting at segment 6 . In Case 5, debulking with a rotablator for the first diagonal branch prior to catheter intervention for the left anterior descending artery led to type 2 bleeding; subsequent balloon inflation for hemostasis resulted in a type 3 rupture. 


\begin{tabular}{|c|c|c|c|c|c|}
\hline Case & $\begin{array}{l}\text { Perforation } \\
\text { site }\end{array}$ & Cause of perforation & Device & ACT (s) & $\begin{array}{c}\text { Cardiac } \\
\text { tamponade }\end{array}$ \\
\hline 1 & $\# 7$ & Balloon (postdilatation) & $\begin{array}{c}\text { Cypher } 2.5 \times 28 \mathrm{~mm} \text {, } \\
\text { unknown balloon (14 atm) }\end{array}$ & 200 & + \\
\hline 2 & \#7 & Stenting & $\begin{array}{l}\text { Driver } 3.5 \times 24 \mathrm{~mm} \\
\text { (unknown pressure) }\end{array}$ & 269 & + \\
\hline 3 & \#2 & Rotablator & 1.5-mm burr & 219 & - \\
\hline 4 & $\# 6$ & Stenting & $\begin{array}{c}\text { Endeavor } \\
3.5 \times 18 \mathrm{~mm}(20 \mathrm{~atm})\end{array}$ & 205 & + \\
\hline 5 & $\# 9$ & Rotablator, balloon & $\begin{array}{l}\text { 1.5-mm burr, Lacrosse } \\
2.0 \times 10 \mathrm{~mm}(1 \mathrm{~atm})\end{array}$ & 187 & + \\
\hline
\end{tabular}

ACT, activated coagulation time.

\begin{tabular}{lcc|}
\hline \multicolumn{2}{l}{ Table 4. Rotablator vs. Balloon } & \\
& Rotablator $(\mathbf{n}=\mathbf{1})$ & Balloon $(\mathbf{n}=\mathbf{4})$ \\
PCPS & 0 & 4 \\
Covered stent & 0 & 3 \\
Pericardiocentesis & 0 & 3 \\
Hemostasis & 1 & 3 \\
Re-bleeding & 0 & $3 / 3$ \\
Emergency surgery & 0 & 4 \\
\hline
\end{tabular}

PCPS, percutaneous cardiopulmonary support.

\section{Results}

\section{Incidence of Perforation}

The number of PCI performed in the referral hospital during the same period was 4,189 ; the rate of type $3 \mathrm{CP}$ requiring surgical intervention was $0.1 \%$. We have had 17 cases $(0.4 \%)$ of $\mathrm{CP}$, which were successfully treated by bail-out catheter procedures during the study period. Non-surgical cases of $\mathrm{CP}$ were all Ellis type 2; 15 perforations were induced by a guidewire, one by rotational atherectomy, and only one was caused by balloon angioplasty $(1.3 \times 10 \mathrm{~mm}$ monorail balloon, $2 \mathrm{~atm}$, $12 \mathrm{~s}$ ) for chronic total occlusion (CTO).

\section{Coronary Lesion Morphology}

Coronary lesion morphology is summarized in Table 2. Target lesion was in the left anterior descending (LAD) artery in 4 cases $(80 \%)$ and the right coronary artery in 1 case $(20 \%)$. Diffuse lesions $(>20 \mathrm{~mm})$ were detected in 4 cases $(80 \%)$; the mean length of the coronary lesions was $31 \mathrm{~mm}$ (range, $12-50 \mathrm{~mm})$. Calcified lesions occurred in 3 cases $(60 \%)$; CTO, small vessel lesion $(<2.5 \mathrm{~mm})$ and ostial lesions were not found. The American Heart Association/American College of
Cardiology (AHA/ACC) classifications were type B2 in only one case (20\%) and type $\mathrm{C}$ in 4 cases $(80 \%)$.

\section{Details of Coronary Perforation}

Case-oriented details of CP are shown in Figure 1 and Table 3. In Case 5, debulking with a rotablator for the first diagonal branch prior to catheter intervention for LAD led to type 2 bleeding; subsequent balloon inflation for hemostasis resulted in a type 3 perforation. The other causes of perforation were rotational atherectomy in 1 case, balloon inflation for postdilatation in 1 case, and stenting in 2 cases. The mean activated coagulation time was $216 \mathrm{~s}$ at the end of catheterization. Cardiac tamponade occurred in all 4 cases of type $3 \mathrm{CP}$ associated with balloon inflation.

\section{Rotational Atherectomy vs. Balloon Inflation}

Although statistical analysis was not available because of the small number of cases, a comparison of type $3 \mathrm{CP}$ induced by rotablator and those by balloons is shown in Table 4 . In the case of rotablator-induced $\mathrm{CP}$, covered stents could not be passed through the calcified perforation site; only prolonged balloon inflation was available for hemostasis. Prolonged balloon inflation was successfully performed, avoiding emergency surgery; however, a torn guidewire was left in the right coronary artery and a pseudoaneurysm requiring surgical repair occurred. In contrast, type $3 \mathrm{CP}$ associated with balloon inflation led to shock with cardiac tamponade requiring percutaneous cardiopulmonary support (PCPS) in all 4 cases. With the exception of 1 case of uncontrollable intrapericardial hemorrhage, pericardiocentesis was performed and temporary hemostasis was achieved with covered stent implantation in 3 cases. However, re-bleeding occurred in 3 cases, and all 4 patients with $\mathrm{CP}$ caused by balloon inflation underwent emergency surgical repair under unstable hemodynamics.

\begin{tabular}{|cccccc|}
\hline \multicolumn{2}{|l}{ Table 5. Details of Surgery and Outcome } & & & & \\
Case & Surgery & $\begin{array}{c}\text { Waiting } \\
\text { time }\end{array}$ & $\begin{array}{c}\text { Peak CK-MB } \\
\text { (IU/L) }\end{array}$ & Morbidity & Outcome \\
1 & Long onlay-patch repair with SVG & $7 \mathrm{~h}$ & 1,436 & LOS, brain ischemia & Death \\
2 & CABG with SVG, felt wrapping & $10 \mathrm{~h}$ & 43 & Brain ischemia & Patient transfer \\
3 & AVR, CABG with SVG, & 7 days & 33 & - & Discharge \\
& felt wrapping, guidewire removal & & & & Discharge \\
4 & CABG with SVG, felt wrapping & $10 \mathrm{~h}$ & 179 & - & Discharge \\
\hline
\end{tabular}

CK-MB, creatine kinase MB; SVG, saphenous vein graft; LOS, low output syndrome; CABG, coronary artery bypass grafting; AVR, aortic valve replacement. 


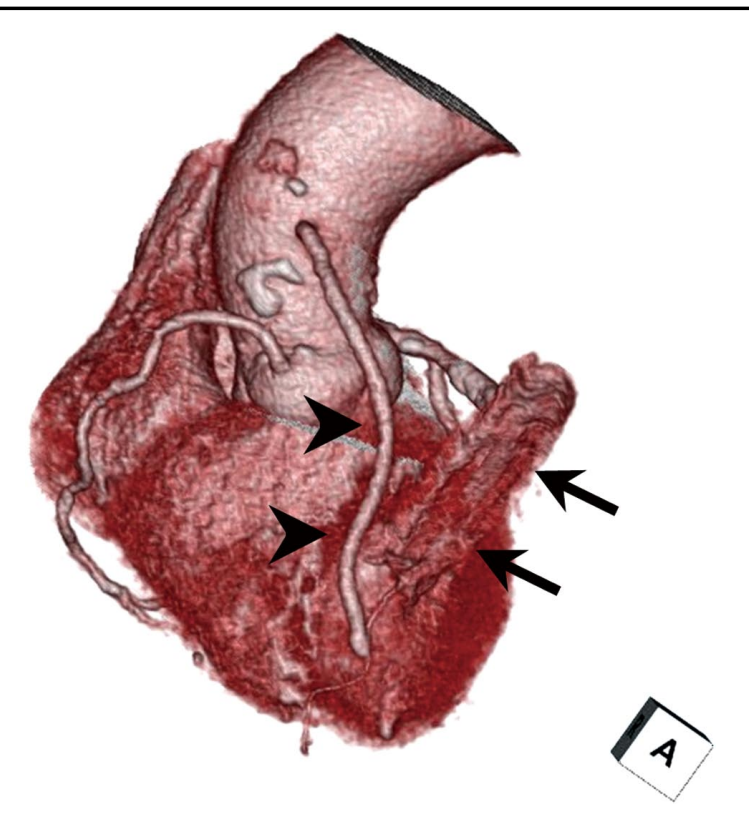

Figure 2. Postoperative 3-dimensional computed tomography scan (Case 2). The ruptured coronary artery and the epicardial tear was widely wrapped with 2 felt strips (arrow) and a saphenous vein graft was used as a conduit for prompt coronary perfusion (arrowheads).

\section{Surgery and Outcome}

A case-oriented summary of the surgery and outcomes are shown in Table 5. Intrapericardial findings were subepicardial hematoma in the case of rotablator-induced CP and persistent arterial bleeding from an epicardial tear in the 4 cases of $\mathrm{CP}$ caused by balloon inflation. In the case of $\mathrm{CP}$ induced by rotational atherectomy, elective surgery was performed followed by hemostasis using prolonged balloon inflation. The waiting time from perforation to surgery was 7 days. All 4 patients with type $3 \mathrm{CP}$ associated with balloon inflation needed emergency surgery; the mean waiting time was $8 \mathrm{~h}$.

We tried long onlay-patch repair with saphenous vein graft (SVG) for the first case; however, the coronary laceration was so severe that it was difficult to achieve complete hemostasis. After this case, we chose felt wrapping with a running overand-over suture of the epicardium and concomitant coronary artery bypass grafting $(\mathrm{CABG})$ with $\mathrm{SVG}$. The mortality rate was $20 \%$. Postoperative levels of creatine kinase MB (CK$\mathrm{MB}$ ) were elevated in 3 cases of balloon-induced CP. In Case 1 , a massive thrombosis developed at the left main trunk during prolonged balloon inflation and the patient died of low output syndrome and hole brain ischemia. In Case 2, the patient had been transferred with PCPS, but PCPS flow was insufficient because of massive intrapericardial hemorrhage. Massive cerebral infarction was discovered after emergency surgery and the patient did not regain consciousness.

\section{Discussion}

CP during PCI ranges from tiny guidewire-induced perforation to massive hemorrhage requiring emergency surgery; Ellis type 3 rupture is still a lethal complication. During the study period, we had 17 cases of type $2 \mathrm{CP}$ and 5 cases of type $3 \mathrm{CP}$. Of the 17 cases of type $2 \mathrm{CP}, 15$ perforations were caused by a guidewire, and only one case was caused by bal- loon angioplasty for CTO. There was no case of CTO among the cases of type $3 \mathrm{CP}$. A Guidewire or small-balloon inflation tends to become a cause of perforation in cases of CTO, and so it may rarely lead to type 3 bleeding that needs surgical repair. CP induced by a large-balloon inflation results in a serious condition compared with rotablator-induced CP. On the other hand, our study showed that type $3 \mathrm{CP}$ occurred in cases of diffuse or calcified lesion. In particular, the case of rotablator-induced type $3 \mathrm{CP}$ involved a calcified lesion and the cases of balloon-induced CP related to diffuse lesions (data not shown). This is logical, considering the principle of rotational atherectomy. ${ }^{14}$ In the present study, there was no case of ACS; the cause of CP was elective PCI in all cases. Considering that $80 \%$ of these cases were AHA/ACC type C and high SYNTAX score ( $>33)$, challenging PCI for complicated coronary lesions for which $\mathrm{CABG}$ is usually chosen would be the direct cause of CP.

Rotablator-induced CP was compared with CP caused by balloon inflation in the present study, although statistical analysis was not performed because of the small number of cases. There was a great difference in regard to hemostasis between the rotablator and balloon cases. We considered this was related to the degree of coronary laceration. We used long onlay-patch repair with SVG in Case 1, which was caused by ballooning for postdilatation. In this case, the coronary laceration was multiple, multi-directional, and severe, and we had much trouble achieving hemostasis. In contrast, we confirmed the perforation site in Case 4 (rotablator-induced CP) as a small hole measuring $2 \mathrm{~mm}$ in diameter in the calcified right coronary artery. In addition, there was an epicardial tear bleeding into the pericardial space in all 4 cases of ballooninduced $\mathrm{CP}$, whereas rotablator-induced $\mathrm{CP}$ led to subepicardial hematoma at most. Balloon inflation seemed to result in not only severe coronary rupture but also epicardial tearing.

As a surgical technique for complete hemostasis, we abandoned SVG patch repair after our experience in Case 1. We now perform felt wrapping of the ruptured coronary artery with TachoComb patch and concomitant CABG with SVG (Figure 2). The basic technique is a running over-and-over suture of the epicardium with felt strips. ${ }^{10} \mathrm{~A}$ CP site is usually separate from an epicardial tear, so felt wrapping that includes the ruptured coronary artery and the epicardial tear is quite simple and effective. Recently, hemostatic patches impregnated with human fibrinogen and thrombin (TachoSil) or autologous pericardial patches are reported as an alternative for Teflon felt, and off-pump surgery is preferred.11,12 We used cardiopulmonary bypass (CPB) for hemodynamic stabilization and because of the massive intrapericardial bleeding in all 4 cases of balloon-induced CP. We believe that such an emergency situation permits the use of CPB. In addition, coronary stenting was performed at the perforation sites before emergency surgery in all 4 cases of CP caused by balloon inflation. Covered stents were used for hemostasis in 3 cases and a bare metal stent was deployed as a guide at the ruptured diagonal branch in Case 5. Although the covered stents could not achieve complete hemostasis, coronary stents were useful for identifying the $\mathrm{CP}$ point under a massive subepicardial hematoma. In the present study, in-hospital mortality of $20 \%$ was acceptable; however, emergency CABG with SVG is not associated with a long-term outcome. Interventional cardiologists should know that type $3 \mathrm{CP}$ leads to low-quality revascularization even in rescue cases. 


\section{Conclusion}

$\mathrm{CP}$ induced by balloon inflation tends to result in a more serious condition than rotablator-induced CP. Especially, the coronary laceration associated with balloon inflation is so severe that re-bleeding tends to occur even if covered stent implantation can temporarily achieve hemostasis. Surgical repair must be done without delay if there is any possibility of re-bleeding. In contrast, conservative management can achieve hemostasis in rotablator-induced type $3 \mathrm{CP}$, but additional surgical intervention would be necessary for untreated coronary lesions and for pseudoaneurysms.

\section{References}

1. Takayama T, Hiro T, Hirayama A. Is angioplasty able to become the gold standard of treatment beyond bypass surgery for patients with multivessel coronary artery disease? Therapeutic strategies for 3-vessel coronary artery disease: OPCAB vs PCI (PCI-Side). Circ J 2010; 74: $2744-2749$.

2. Nishimi M, Tashiro T. Off-pump coronary artery bypass vs percutaneous coronary intervention: Therapeutic strategies for 3-vessel coronary artery disease: OPCAB vs PCI (OPCAB-Side). Circ J 2010; 74: $2750-2757$.

3. Ellis SG, Ajluni S, Arnold AZ, Popma JJ, Bittl JA, Eigler NL, et al. Increased coronary perforation in the new device era: Incidence, classification, management, and outcome. Circulation 1994; 90: $2725-$ 2730.

4. Seshadri N, Whitlow PL, Acharya N, Houghtaling P, Blackstone EH, Ellis SG. Emergency coronary artery bypass surgery in the contemporary percutaneous coronary intervention era. Circulation 2002; 106: $2346-2350$.
5. Fukutomi T, Suzuki T, Popma JJ, Hosokawa H, Yokoya K, Inada T, et al. Early and late clinical outcomes following coronary perforation in patients undergoing percutaneous coronary intervention. Circ J 2002; 66: 349-356.

6. Javaid A, Buch AN, Satler LF, Kent KM, Suddath WO, Lindsay J Jr, et al. Management and outcomes of coronary artery perforation during percutaneous coronary intervention. Am J Cardiol 2006; 98: 911 914.

7. Shirakabe A, Takano H, Nakamura S, Kikuchi A, Sasaki A, Yamamoto $\mathrm{E}$, et al. Coronary perforation during percutaneous coronary intervention. Int Heart $J$ 2007; 48: $1-9$.

8. Shimony A, Zahger D, Van Straten M, Shalev A, Gilutz H, Ilia R, et al. Incidence, risk factors, management and outcomes of coronary artery perforation during percutaneous coronary intervention. Am J Cardiol 2009; 104: 1674-1677.

9. Roy P, de Labriolle A, Hanna N, Bonello L, Okabe T, Pinto Slottow $\mathrm{TL}$, et al. Requirement for emergent coronary artery bypass surgery following percutaneous coronary intervention in the stent era. Am J Cardiol 2009; 103: 950-953.

10. Inoue Y, Ueda T, Taguchi S, Kashima I, Koizumi K, Noma S. Teflon felt wrapping repair for coronary perforation after failed angioplasty. Ann Thorac Surg 2006; 82: 2312-2314.

11. Celiento M, Scioti G, Pratali S, Bortolotti U. Repair of coronary artery perforation following angioplasty using TachoSil patches. Interact Cardiovasc Thorac Surg 2010; 10: 328-330.

12. El Oumeiri B, Lipski A, Desmet JM. Off-pump treatment of coronary artery perforation after percutaneous intervention with a pericardial patch. Interact Cardiovasc Thorac Surg 2005; 4: 509-510.

13. Sianos G, Morel MA, Kappetein AP, Morice MC, Colombo A, Dawkins K, et al. The SYNTAX Score: An angiographic tool grading the complexity of coronary artery disease. EuroIntervention 2005; 1: 219-227.

14. Hinohara T. Percutaneous coronary intervention: Current perspective. Keio J Med 2001; 50: 152-160. 